\title{
Crystallization behavior of milk fat obtained from linseed-fed cows
}

\author{
K. Smet, ${ }^{\star 1}$ K. Coudijzer, ${ }^{\star}$ E. Fredrick, † S. De Campeneere,‡ J. De Block, ${ }^{\star}$ J. Wouters,§ K. Raes,\# \\ and K. Dewettinck† \\ *Technology and Food Science Unit, Institute for Agricultural and Fisheries Research (ILVO), Melle B-9090, Belgium \\ †Laboratory of Food Technology and Engineering, Department of Food Safety and Food Quality, Faculty of Bioscience Engineering, \\ Ghent University, Ghent B-9000, Belgium \\ ‡Unit Animal Sciences, Institute for Agricultural and Fisheries Research (ILVO), Melle B-9090, Belgium \\ §Laboratoire de Chimie Biologique Structurale, Département de Chimie, Faculté des Sciences, Facultés Universitaires Notre Dame de la Paix, \\ Namur B-5000, Belgium \\ \#Research Group EnBiChem, Department of Industrial Engineering and Technology, University College West-Flanders, Kortrijk B-8500, Belgium
}

\section{ABSTRACT}

Milk with an increased content of unsaturated fatty acids was obtained by incorporating $60 \%$ of extruded linseed into the concentrate of cows. Two groups of Holstein cows (3 animals/group) were fed a concentrate (control or linseed enriched) together with the same roughage diet (ad libitum). After an adaptation period of $3 \mathrm{wk}$, evening and morning milk samples were collected every $7 \mathrm{~d}$ for $3 \mathrm{wk}$. Milk was decreamed and anhydrous milk fat (AMF) was isolated from the fat fraction by using the Bureau of Dairy Industries method. The objective of this study was to investigate if the crystallization mechanism of milk fat changed when the content of unsaturated fatty acids was increased. Therefore, the crystallization behavior of a milk fat enriched with unsaturated fatty acids was compared with that of a control milk fat. Nonisothermal crystallization was investigated with differential scanning calorimetry, and 1-step and 2-step isothermal crystallization behaviors were investigated using pulsed nuclear magnetic resonance, differential scanning calorimetry, and x-ray diffraction. A higher content of unsaturated fatty acids in AMF resulted in an increased proportion of low melting triglycerides. These triglycerides lowered the solid fat content profile, particularly at refrigerator temperatures. Furthermore, they induced some changes in the crystallization and melting behaviors of milk fat compared with a control AMF, although no fundamental changes in the crystallization mechanism could be revealed. Even though a lower melting point could be observed for milk fat with a higher content of unsaturated fatty acids, a similar degree of supercooling was needed to initiate crystallization, resulting in a shift in onset temperature of crystallization toward lower temperatures. In addition, slower crystallization

Received July 24, 2009.

Accepted October 29, 2009

${ }^{1}$ Corresponding author: karen.smet@ilvo.vlaanderen.be kinetics were measured, such as a lower nucleation rate and longer induction times, although crystallization occurred in a similar polymorphic crystal lattice. During melting, a shift in offset temperature toward lower temperatures could be observed for the 3 melting fractions of AMF in addition to a higher proportion of low melting triglycerides. These results demonstrate that a higher content of unsaturated fatty acids has some effect on the crystallization behavior of milk fat. This knowledge could be used to produce dairy products of similar or superior quality compared with conventional products by intervening in the production process of dairy products.

Key words: milk fat, differential scanning calorimetry, pulsed nuclear magnetic resonance, X-ray diffraction

\section{INTRODUCTION}

There is considerable interest in altering the fatty acid composition of milk with the overall aim to improve the long-term health of consumers. Important targets involve reducing the amounts of medium-chain saturated fatty acids together with enhancing oleic acid, vaccenic acid and rumenic acid (Dewhurst et al., 2006). Several human intervention trials were performed investigating the potential health benefits of a butter-fat modified through manipulations by the cows diets to increase the unsaturated:saturated fatty acid ratio. Noakes et al. (1996), Poppitt et al. (2002), and Seidel et al. (2005) measured a significant decrease of the low-density lipoprotein (LDL):high-density lipoprotein ratio, mainly because of a decrease in LDL after consumption of fatmodified dairy products. In contrast, Tholstrup et al. (1998) failed to detect a reduction in LDL concentration after a diet with modified milk fat. They suggested that the higher content of trans fatty acids in the applied modified milk fat counteracted the cholesterol-lowering effect. These studies showed that fat modification of dairy products represents a potential strategy to lower 
the risk of coronary heart disease without any appreciable change in customary eating patterns.

The fatty acid composition of milk fat can be improved by fractionation processes, genetic manipulation of the dairy cow, or specific feeding strategies (Kaylegian et al., 1993). When using the latter strategy, the extensive metabolism of lipids that can occur in the rumen needs to be taken into consideration (Ashes et al., 1997; Dewhurst et al., 2003; Givens and Shingfield, 2003; Lock and Bauman, 2004). Intensive research has shown that a more unsaturated fatty acid composition of milk can be obtained, for example, by feeding unsaturated fat supplements or by changing the basal forage toward more fresh leafy grass or red clover silage (Ashes et al., 1997; Dewhurst et al., 2006).

However, an increase in unsaturated fatty acids can influence the physical properties of fat-rich dairy products. Studies have shown that cold-spreadability of butter is positively correlated to the percentage of unsaturated fatty acids in butter fat (e.g., Bayourthe et al., 2000; Baer et al., 2001; Bobe et al., 2003; Couvreur et al., 2006). Chen et al. (2004) reported that butter, yogurt, ice cream, and cheese made from milk enriched with unsaturated fatty acids showed a softer texture than products made from control milk. Jones et al. (2005) obtained similar results for butter and cheese enriched with conjugated linoleic acid (CLA), whereas Smet et al. [K. Smet, J. De Block, P. Van Der Meeren (Particle and Interfacial Technology Group, Faculty of Bioscience Engineering, Ghent University, Ghent B-9000, Belgium), K. Raes, K. Dewettinck, and K. Coudijzer; unpublished data] observed softer ice cream with a faster melting rate when the content of unsaturated fatty acids was increased. Besides influencing the texture of dairy products, a modified fatty acid profile may also interfere in the production process. For the production of butter, buttermilk had to be removed carefully after the churning of unsaturated butters because they were very soft. In addition, longer churning times were reported (Ashes et al., 1997). Gonzalez et al. (2003) observed for ice cream a decreased viscosity of the ice cream mix, which may be important from an engineering perspective during processing.

Although several studies have demonstrated an influence of unsaturated milk fat on the physical properties of dairy products, very little research has been done to reveal the fundamental background of this phenomenon. The functional properties of milk fat are strongly related to the amount and type of milk fat crystals at the temperature of application. Moreover, the phase behavior is complicated because of the polymorphism of the solid phase (Taylor and MacGibbon, 2002). Intensive research in the past has resulted in a more comprehensive insight in the complex behavior of milk fat, using techniques such as pulsed nuclear magnetic resonance (pNMR), differential scanning calorimetry (DSC), and x-ray synchrotron diffraction (e.g., ten Grotenhuis et al., 1999; Lopez et al., 2005).

The objective of this study was to investigate if the crystallization mechanism of milk fat changed when the content of unsaturated fatty acids was increased. Therefore, the crystallization behavior of a milk fat enriched with unsaturated fatty acids was compared with the behavior of a control milk fat. Nonisothermal crystallization was investigated with DSC, and 1-step and 2-step isothermal crystallization behaviors were investigated using pNMR, DSC, and x-ray diffraction (XRD).

\section{MATERIALS AND METHODS}

\section{Materials}

Milk with an increased content of unsaturated fatty acids was obtained by incorporating $60 \%$ of extruded linseed into the concentrate of cows. Two groups of Holstein cows ( 3 animals/group) were fed a concentrate (control or linseed enriched) together with the same roughage diet (ad libitum). A detailed composition of both diets is reported in Smet et al. (2009). After an adaptation period of $3 \mathrm{wk}$, evening and morning milk samples were collected every $7 \mathrm{~d}$ for 3 wk. Milk was decreamed, and anhydrous milk fat (AMF) was isolated from the fat fraction by using the Bureau of Dairy Industries (BDI) method as described by Driessen et al. (1977). Briefly, the BDI reagent consisted of $50 \mathrm{~g}$ of Graham's salt (Merck, Darmstadt, Germany), $50 \mathrm{~g}$ of urea (Merck), $24 \mathrm{~mL}$ of Triton-X100 (Merck), and 100 $\mathrm{mL}$ of isopropanol (Panreac, Barcelona, Spain), diluted with demineralized water to $1 \mathrm{~L}$. In a $500-\mathrm{mL}$ volumetric flask, $100 \mathrm{~mL}$ of cream was mixed with $400 \mathrm{~mL}$ of BDI reagent. The flask was totally immersed in a hot-water bath heated at $80^{\circ} \mathrm{C}$, and a fat column developed in the neck of the flask. After isolation of the fat fraction, the solvent residue was removed in a vacuum oven at $40^{\circ} \mathrm{C}$. This procedure was repeated for 3 consecutive weeks. The isolated AMF was pooled for the control milk fat (CMF) and the milk fat with increased unsaturated fatty acid content (UMF) and stored at $-18^{\circ} \mathrm{C}$ until analysis. The chemical characterization of AMF was determined based on its fatty acid composition using GC as reported by Smet et al. (2008).

\section{DSC}

Nonisothermal crystallization of CMF and UMF was monitored using DSC. Crystallization curves were obtained with a TA Q1000 DSC (TA Instruments, New Castle, DE) with a refrigerated cooling system. The 


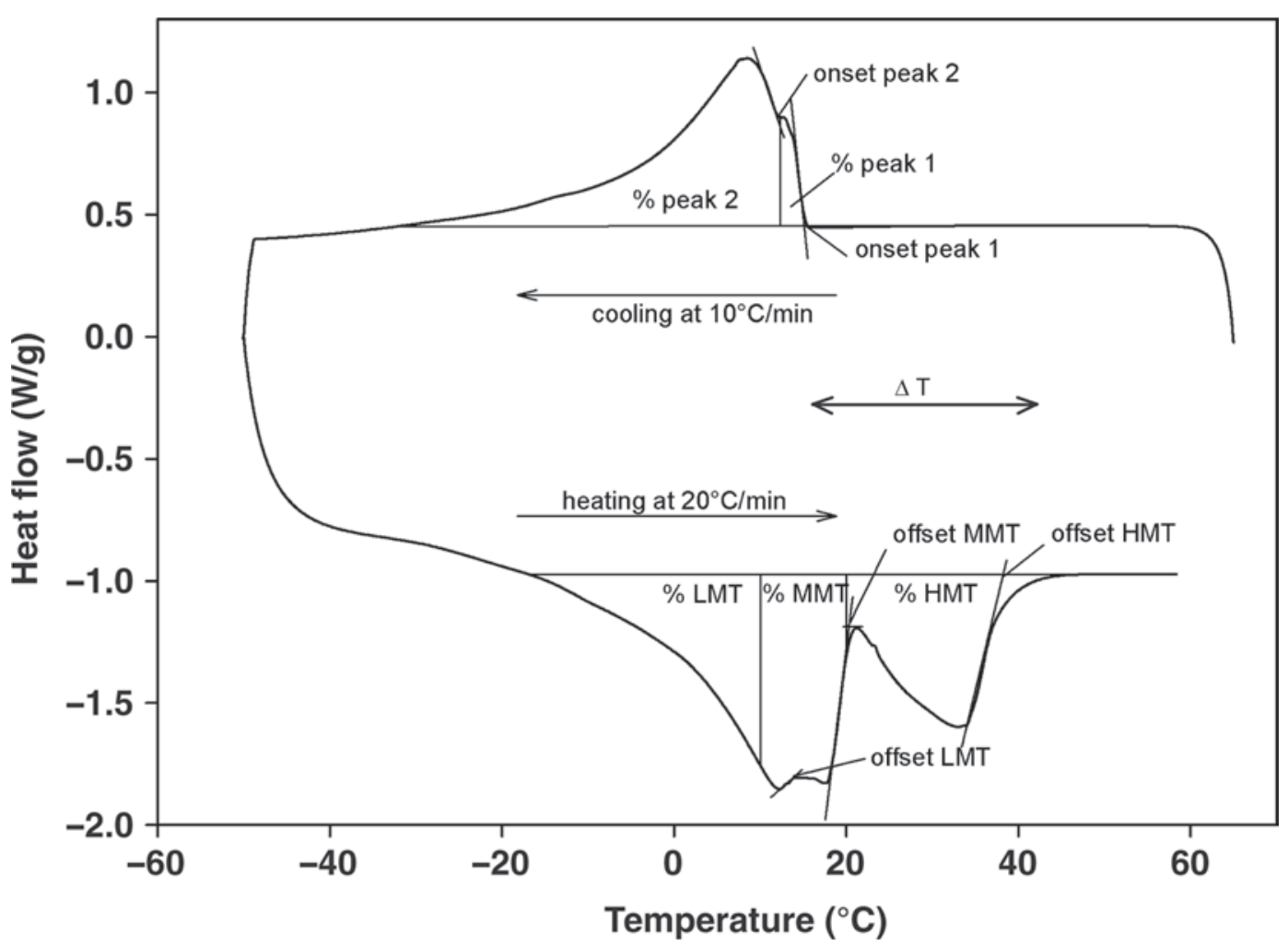

Figure 1. Parameters derived from nonisothermal crystallization of anhydrous milk fat obtained with differential scanning calorimetry. The applied time-temperature program was as follows: holding at $65^{\circ} \mathrm{C}$ for 15 min to ensure a completely liquid state, cooling at $10^{\circ} \mathrm{C} / \mathrm{min}$ to $-50^{\circ} \mathrm{C}$, holding for $5 \mathrm{~min}$, and then heating at $20^{\circ} \mathrm{C} / \mathrm{min}$ to $65^{\circ} \mathrm{C}$. LMT $=$ low melting triglycerides; MMT = middle melting triglycerides; HMT $=$ high melting triglycerides; onset temperature $=$ temperature at beginning of crystallization; offset temperature $=$ temperature at ending of melting.

DSC was calibrated with indium (TA Instruments), azobenzene (Sigma-Aldrich, Bornem, Belgium), and undecane (Acros Organics, Geel, Belgium) before analyses. Nitrogen was used to purge the system. Melted fat $(5-15 \mathrm{mg})$ was sealed in hermetic aluminum pans and an empty pan was used as a reference. The applied time-temperature program for nonisothermal crystallization was as follows: holding at $65^{\circ} \mathrm{C}$ for $15 \mathrm{~min}$ to ensure a completely liquid state, cooling at $10^{\circ} \mathrm{C} / \mathrm{min}$ to $-50^{\circ} \mathrm{C}$, holding for $5 \mathrm{~min}$, and then heating at $20^{\circ} \mathrm{C} /$ min to $65^{\circ} \mathrm{C}$. Crystallization and melting peaks were identified with Universal Analysis software (TA Instruments). Onset temperatures and offset temperatures were calculated as shown in Figure 1, whereas fractions of triglycerides were identified according to Deffense (1993). The fraction of low melting triglycerides (LMT) was characterized by melting temperatures $<10^{\circ} \mathrm{C}$, the fraction of middle melting triglycerides (MMT) melted between 10 and $20^{\circ} \mathrm{C}$, and the fraction of high melting triglycerides (HMT) melted $>20^{\circ} \mathrm{C}$.

Two supercooling temperatures were selected for investigating the physicochemical behavior of $\mathrm{CMF}$ and UMF during isothermal crystallization, based on their final melting temperature as obtained with nonisothermal crystallization (CMF: $38.5^{\circ} \mathrm{C}$; UMF: $36.8^{\circ} \mathrm{C}$ ). One-step crystallization was investigated at a supercooling of $14.8^{\circ} \mathrm{C}$, indicating that crystallization temperatures of 23.7 and $22.0^{\circ} \mathrm{C}$ were applied for $\mathrm{CMF}$ and UMF, respectively. For 2-step crystallization, a supercooling of $31.8^{\circ} \mathrm{C}$ was used, implying crystallization temperatures of 6.7 and $5.0^{\circ} \mathrm{C}$ for $\mathrm{CMF}$ and $\mathrm{UMF}$, respectively.

Isothermal crystallization kinetics were investigated using DSC with the following time-temperature program: holding at $65^{\circ} \mathrm{C}$ for $10 \mathrm{~min}$ to ensure a completely liquid state, cooling at $10^{\circ} \mathrm{C} / \mathrm{min}$ to the appropriate crystallization temperature, holding for a given crystallization time to ensure total crystallization, and then heating at $20^{\circ} \mathrm{C} / \mathrm{min}$ to $65^{\circ} \mathrm{C}$. For 1-step crystallization (supercooling of $14.8^{\circ} \mathrm{C}$ ), the induction time to crystallization, the peak maximum of melting, and the peak width of the melting curve at half height corrected for melting enthalpy were calculated. For 2-step crystallization (supercooling of $31.8^{\circ} \mathrm{C}$ ), the onset temperature 
of crystallization, the induction time to the second crystallization step, and the peak maximum of melting were calculated.

\section{pNMR}

The solid fat content (SFC) profiles of CMF and UMF were performed using pNMR with a daily-calibrated Minispec pc 20 (Bruker, Karlsruhe, Germany). Liquefied fat was transferred into pNMR tubes and held at $65^{\circ} \mathrm{C}$ for 30 min to eliminate any thermal history. Afterward, the pNMR tubes were quenched cooled with liquid nitrogen and placed in a water bath at $5^{\circ} \mathrm{C}$. After an incubation of $1 \mathrm{~h}$, SFC was determined with pNMR. Then, the temperature of the water bath was increased with $5^{\circ} \mathrm{C}$ and again, the SFC was determined after $1 \mathrm{~h}$ of incubation. This procedure was repeated until the AMF was totally liquefied. All measurements were done in triplicate.

The increase in solid fat during isothermal crystallization of CMF and UMF was measured by pNMR at a supercooling of 14.8 and $31.8^{\circ} \mathrm{C}$. Liquefied fat was transferred into pNMR tubes and held at $65^{\circ} \mathrm{C}$ for 30 min to eliminate any thermal history. Afterward, the tubes were placed in a thermostatic water bath at a given crystallization temperature. Readings of the amount of solid fat were taken at appropriate time intervals and a separate tube was used for each measurement. The start of the isothermal period was taken 1 min after transfer to the water bath. Each analysis was performed in triplicate.

\section{$X R D$}

Short spacings of CMF and UMF were measured during isothermal crystallization (supercooling of 14.8 and $31.8^{\circ} \mathrm{C}$ ) on an X'pert Pro Diffractometer (PANalytical, Almelo, the Netherlands), including a PW 3050/60 ( $\theta / \theta)$ goniometer and an Anton Paar TTK-450 sample stage (Anton Paar Benelux, Sint-Martens-Latem, Belgium). An external water bath was used to apply a given isothermal crystallization time-temperature protocol. The diffractometer was equipped with a sealed $\mathrm{Cu}$-x-ray tube, $0.04 \mathrm{rad}$ primary and secondary Soller slits (size $2 ")$ and a Ni-filter that produces $\mathrm{Cu} \mathrm{K} \alpha 1$ x-ray beam ( $\lambda$ $=1.541 \AA$ ). The sample was scanned from $15^{\circ} 2 \theta$ to 27 ${ }^{\circ} 2 \theta$, increasing with a step size of $0.008^{\circ} 2 \theta$. Wide angle x-ray diffraction (WAXD) patterns were smoothed with a Fourier transformation by the X'pert High Score software (PANalytical). Spreadsheets were generated of each scan with the diffraction intensity as function of the incident beam angle, from which 2-dimensional plots were drawn in SigmaPlot 10 for Windows (version 10.0, Systat Software Inc., Chicago, IL).

\section{Statistical Analysis}

Statistical analysis of the data was performed using the SPSS statistical package (release 16.0, SPSS, Chicago, IL). Fatty acid composition and parameters obtained with DSC were analyzed using the independent samples $t$-test with milk fat as fixed factor.

\section{RESULTS}

\section{Fatty Acid Profile of AMF}

The fatty acid composition of CMF and UMF is reported in Table 1. Briefly, significant differences could be observed between both milk fats. The UMF had a lower fraction of saturated fatty acids (SFA; $P<0.001$ ), mainly because of decreased contents of C10:0, C12:0, and C16:0, even though an increase in C18:0 could be observed for UMF. The fraction of monounsaturated fatty acids (MUFA) was higher for UMF compared with CMF $(P<0.001)$, mainly because of a higher content of C18:1 cis-9 and C18:1 trans-10, trans-11. An increase in the polyunsaturated fatty acid (PUFA) fraction could also be observed for UMF, mainly caused by an increase in C18:2 (n-6), C18:3 (n-3), and CLA ( $P$ $<0.001)$. The higher fraction of total trans fatty acids of UMF was mainly caused by an increase in C18:1 trans-10, trans-11, whereas the higher CLA fraction of UMF could be attributed to an increased content of cis-9, trans-11 CLA.

\section{SFC Profile of AMF}

The SFC profiles of both CMF and UMF are illustrated in Figure 2. At $5^{\circ} \mathrm{C}$, the $\mathrm{SFC}$ of $\mathrm{CMF}$ was $60 \%$ compared with $46 \%$ for UMF. When the temperature increased, the difference in SFC between both milk fats decreased, suggesting smaller differences in physical properties between CMF and UMF at higher temperatures. Both milk fats were totally melted between 35 and $40^{\circ} \mathrm{C}$.

\section{Nonisothermal Crystallization Behavior}

During nonisothermal crystallization of AMF (Figure 3A), 2 crystallization peaks were observed, which can be described with a typical onset temperature, indicating the start of crystallization (Figure 1). Crystallization started at $15.4^{\circ} \mathrm{C}$ for CMF, whereas UMF only crystallized at $14.4^{\circ} \mathrm{C}$. This shift toward lower crystallization temperatures for UMF was even more emphasized for the second crystallization peak. The contribution of each crystallization peak to the total crystallization heat was also shifted when comparing both milk fats. 
The first crystallization peak of UMF measured only $3.5 \%$, whereas for CMF, a peak of $9.2 \%$ could be observed (Table 2).

The melting curve of AMF (Figure 3B) obtained after nonisothermal crystallization can be divided into 3 fractions according to their melting points (Figure 1; Deffense, 1993; Kaylegian and Lindsay, 1995), and each fraction can be identified with a typical offset temperature, defining the temperature when melting of a peak is ended. When comparing UMF with CMF, the offset temperature was shifted toward lower temperatures for all fractions (Table $2 ; P \leq 0.011$ ). In addition, the pro- portion of the different fractions was influenced by the milk fat composition. Whereas for CMF the 3 fractions were represented in similar proportions, UMF contained more LMT $(P<0.001)$, compensated by lower contents of $\operatorname{MMT}(P<0.001)$ and $\operatorname{HMT}(P=0.004)$.

Finally, the degree of supercooling $(\Delta \mathbf{T})$ was calculated as the difference between the offset temperature of melting and the onset temperature of crystallization (Figure 1). No difference could be noted between CMF and UMF (Table 2: $P=0.38$ ), indicating that for both milk fats a similar degree of supercooling was needed to induce crystallization.

Table 1. Fatty acid composition (mg of fatty acid/g of total fatty acid methyl esters) of milk fat from cows fed a control diet (CMF) or a diet containing extruded linseed (UMF), where values are the mean of $n=3$ determinations (adapted from Smet et al., 2009)

\begin{tabular}{|c|c|c|c|c|}
\hline Fatty acid $^{1}$ & $\mathrm{CMF}$ & UMF & SEM & $P$-value \\
\hline C6:0 & 21.4 & 17.6 & 1.11 & 0.086 \\
\hline C8:0 & 10.6 & 8.09 & 0.702 & 0.069 \\
\hline C10:0 & 32.4 & 27.4 & 0.915 & 0.001 \\
\hline C12:0 & 42.7 & 35.8 & 1.27 & 0.001 \\
\hline C14:0 & 102 & 99.7 & 1.29 & 0.300 \\
\hline $\mathrm{C} 15: 0$ iso & 4.37 & 4.48 & 0.0431 & 0.202 \\
\hline $\mathrm{C} 15: 0$ anteiso & 2.41 & 2.40 & 0.639 & 0.014 \\
\hline C15:0 & 8.18 & 6.98 & 0.192 & $<0.001$ \\
\hline C16:0 & 346 & 236 & 16.7 & $<0.001$ \\
\hline $\mathrm{C} 17: 0$ iso & 4.23 & 4.02 & 0.0734 & 0.162 \\
\hline $\mathrm{C} 17: 0$ anteiso & 2.35 & 2.33 & 0.0454 & 0.905 \\
\hline C17:0 & 4.05 & 3.44 & 0.107 & $<0.001$ \\
\hline C18:0 & 85.3 & 116 & 5.01 & $<0.001$ \\
\hline $\mathrm{C} 20: 0$ & 1.32 & 1.28 & 0.0334 & 0.542 \\
\hline C21:0 & 0.24 & 0.11 & 0.0238 & 0.002 \\
\hline $\mathrm{C} 22: 0$ & 0.43 & 0.48 & 0.0480 & 0.603 \\
\hline C24:0 & 0.27 & 0.32 & 0.337 & 0.500 \\
\hline C14:1 cis-9 & 8.37 & 9.60 & 0.314 & 0.042 \\
\hline C16:1 cis-9 & 21.1 & 14.6 & 1.01 & $<0.001$ \\
\hline C17:1 cis-9 & 3.45 & 2.32 & 0.180 & $<0.001$ \\
\hline C18:1 cis-9 & 182 & 241 & 9.13 & $<0.001$ \\
\hline C18:1 cis-11 & 3.68 & 2.31 & 0.211 & $<0.001$ \\
\hline C20:1 cis-11 & 0.0966 & 0.304 & 0.0332 & $<0.001$ \\
\hline C16:1 trans-9 & 0.462 & 1.36 & 0.153 & $<0.001$ \\
\hline C18:1 trans- 10, trans-11 & 16.7 & 36.8 & 3.04 & $<0.001$ \\
\hline CLA cis-9, trans-11 & 5.64 & 15.5 & 1.49 & $<0.001$ \\
\hline CLA trans-10, cis- 12 & 0.846 & 1.06 & 0.0344 & $<0.001$ \\
\hline CLA trans, trans & 0.148 & 0.608 & 0.0902 & 0.004 \\
\hline C18:2 (n-6) & 13.0 & 16.7 & 0.569 & $<0.001$ \\
\hline C18:3 (n-6) & 0.251 & 0.322 & 0.0412 & 0.421 \\
\hline $\mathrm{C} 20: 2(\mathrm{n}-6)$ & 0.212 & 0.247 & 0.0127 & 0.202 \\
\hline C20:3 (n-6) & 1.04 & 0.977 & 0.0674 & 0.686 \\
\hline C20:4 (n-6) & 0.863 & 0.965 & 0.0364 & 0.172 \\
\hline C18:3 (n-3) & 3.83 & 10.8 & 1.05 & $<0.001$ \\
\hline C20:5 (n-3) & 0.581 & 0.812 & 0.0553 & 0.029 \\
\hline $\mathrm{C} 22: 5(\mathrm{n}-3)$ & 0.765 & 0.830 & 0.0212 & 0.129 \\
\hline SFA (\%) & 71.8 & 61.3 & 1.59 & $<0.001$ \\
\hline MUFA (\%) & 25.3 & 33.4 & 1.23 & $<0.001$ \\
\hline PUFA (\%) & 2.92 & 5.29 & 0.358 & $<0.001$ \\
\hline Total trans (\%) & 2.56 & 5.99 & 0.52 & $<0.001$ \\
\hline Total CLA (\%) & 0.713 & 1.86 & 0.173 & $<0.001$ \\
\hline n-6 fatty acids (\%) & 1.65 & 2.08 & 0.660 & $<0.001$ \\
\hline n-3 fatty acids (\%) & 0.556 & 1.35 & 0.120 & $<0.001$ \\
\hline
\end{tabular}

${ }^{1} \mathrm{CLA}=$ conjugated linoleic acid, SFA = saturated fatty acids, MUFA = monounsaturated fatty acids, PUFA $=$ polyunsaturated fatty acids. 


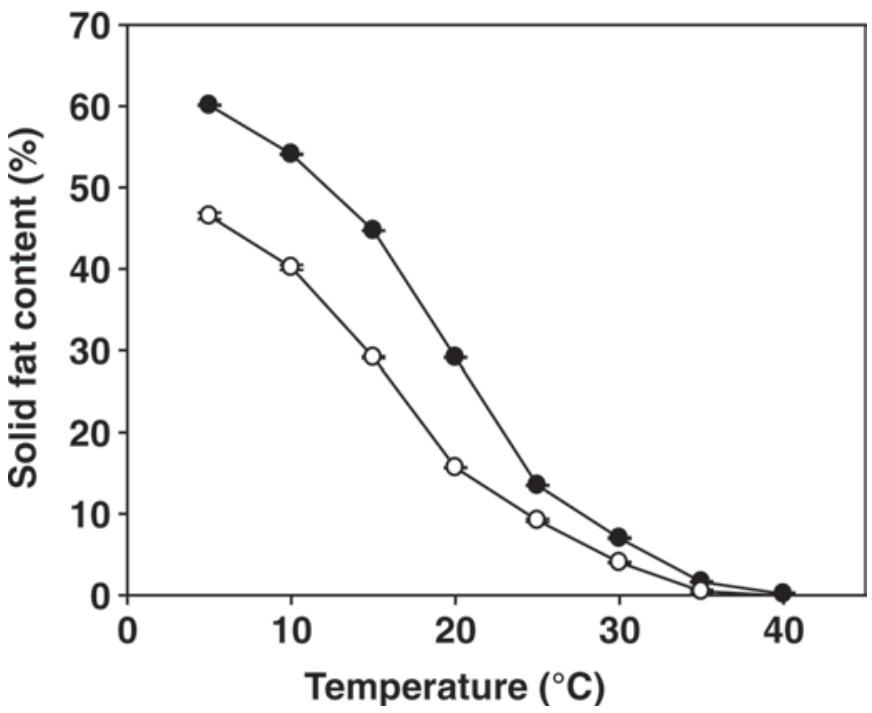

Figure 2. Solid fat content (\%) profile of milk fat from cows fed a control diet $(\bullet)$ or a diet containing extruded linseed $(\bigcirc)$, where values are the mean of $\mathrm{n}=3$ determinations.

\section{Isothermal 1-Step Crystallization Behavior}

Isothermal 1-step crystallization was investigated at a supercooling of $14.8^{\circ} \mathrm{C}$, implying crystallization temperatures of 23.7 and $22.0^{\circ} \mathrm{C}$ for $\mathrm{CMF}$ and $\mathrm{UMF}$, respectively. Because these temperatures are above the melting points of both LMT and MMT, it is only HMT that is crystallizing.

In Figure 4A, SFC is presented as a function of isothermal time. After an induction period of about 35 min, primary crystallization started to reach a plateau after about 150 min. During this 1-step crystallization, triglycerides were directly crystallized in the $\beta^{\prime}$ polymorph for both milk fats, because short spacings could be observed at 4.25 and $3.85 \AA$ (Figure 5, panels A and B). However, for CMF, some additional diffraction peaks could be detected at 4.37 and $4.11 \AA$, suggesting the formation of an additional $\beta^{\prime}$ polymorph (Timms, 1980).

When investigating the crystallization kinetics more quantitatively, it is clear from Figure 4A that a higher SFC could be observed at the end of crystallization for CMF compared with UMF, although a similar driving force (supercooling of $14.8^{\circ} \mathrm{C}$ ) was applied. An equal supercooling does not imply equal SFC, because the supercooling is related to the final melting point, but it does not account for the profile of melting (Table 2). Based on isothermal DSC measurements, the induction time to crystallization could be accurately determined, showing a longer induction time for UMF (35.2 $\mathrm{min})$ than for $\mathrm{CMF}$ (26.8 min; $P=0.014)$. In addition, a shift in the temperature at peak maximum of melting could be observed toward lower temperatures for UMF $(P=0.027)$, whereas its peak width at half height was increased (Table $3 ; P<0.001$ ).

\section{Isothermal 2-Step Crystallization Behavior}

Isothermal 2-step crystallization was investigated at a supercooling of $31.8^{\circ} \mathrm{C}$, implying crystallization temperatures of 6.7 and $5.0^{\circ} \mathrm{C}$ for $\mathrm{CMF}$ and $\mathrm{UMF}$, respectively. Because these temperatures are below the melting points of all 3 fractions, LMT, MMT, and HMT would crystallize.

The SFC profile, presented in Figure 4B, clearly showed 2 steps of crystallization. With this degree of supercooling, crystallization already started during the establishing of the desired temperature for crystallization for both milk fats, although the rate of crystallization was higher for CMF than for UMF. A first plateau was reached after about 10 min with a significantly higher SFC for CMF $( \pm 38 \%)$ compared with

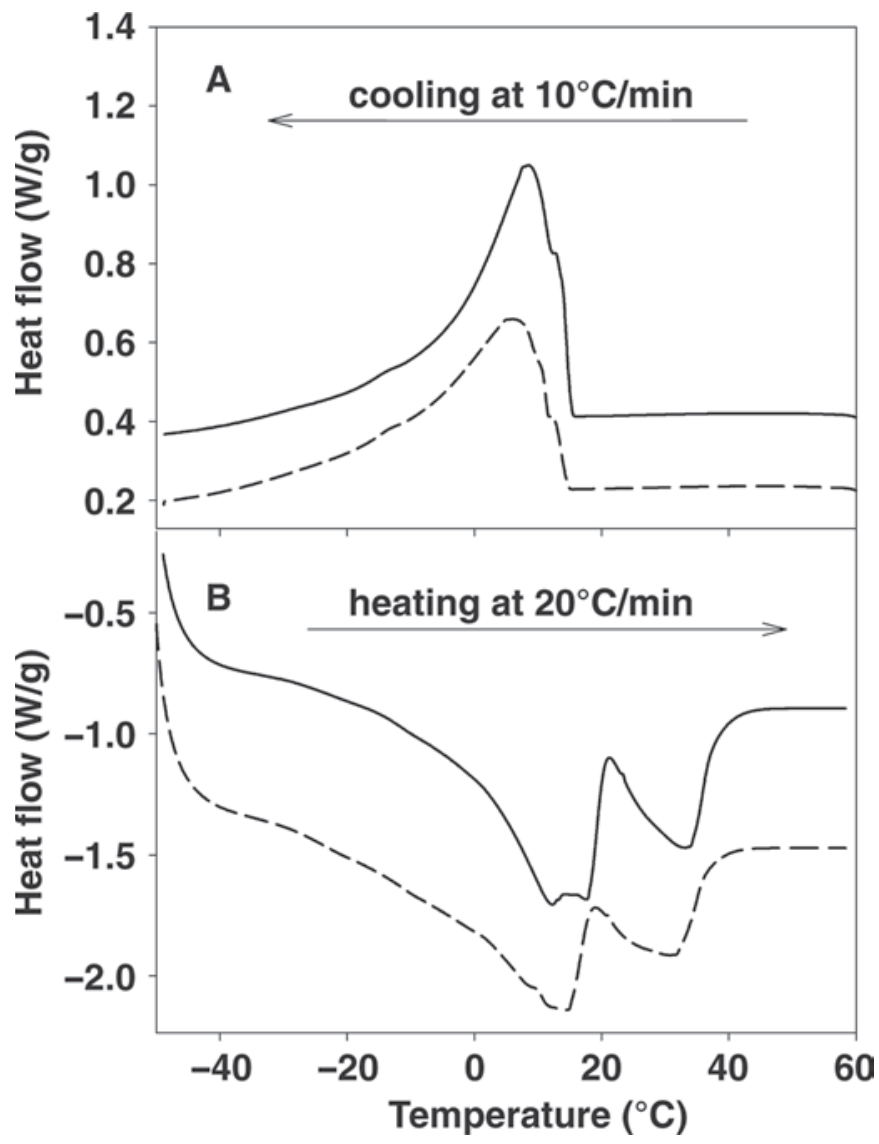

Figure 3. Nonisothermal crystallization and subsequent melting of milk fat from cows fed a control diet (-) or a diet containing extruded linseed $(---)$. A) Nonisothermal crystallization curves (cooling at $10^{\circ} \mathrm{C} / \mathrm{min}$ from $65^{\circ} \mathrm{C}$ to $-50^{\circ} \mathrm{C}$ ); B) melting curves (heating at $20^{\circ} \mathrm{C} /$ min from $-50^{\circ} \mathrm{C}$ to $65^{\circ} \mathrm{C}$ ). 
Table 2. Parameters derived from nonisothermal crystallization ${ }^{1}$ of anhydrous milk fat obtained with differential scanning calorimetry

\begin{tabular}{|c|c|c|c|c|}
\hline \multirow[b]{2}{*}{ Parameter } & \multicolumn{2}{|c|}{ Milk fat ${ }^{2}$} & \multirow[b]{2}{*}{ SEM } & \multirow[b]{2}{*}{$P$-value } \\
\hline & CMF & UMF & & \\
\hline \multicolumn{5}{|l|}{ Onset of crystallization ${ }^{3}\left({ }^{\circ} \mathrm{C}\right)$} \\
\hline First peak crystallization & 15.35 & 14.42 & 0.20 & 0.009 \\
\hline Second peak crystallization & 12.07 & 10.85 & 0.28 & 0.014 \\
\hline \multicolumn{5}{|l|}{ Fractions of crystallization (\%) } \\
\hline First peak crystallization & 9.21 & 3.50 & 1.20 & 0.005 \\
\hline Second peak crystallization & 90.79 & 96.53 & 1.20 & 0.005 \\
\hline \multicolumn{5}{|l|}{ Offset of melting ${ }^{4}\left({ }^{\circ} \mathrm{C}\right)$} \\
\hline Low melting triglycerides & 14.05 & 10.27 & 0.70 & $<0.001$ \\
\hline Middle melting triglycerides & 19.33 & 17.73 & 0.36 & 0.011 \\
\hline High melting triglycerides ${ }^{5}$ & 38.48 & 36.76 & 0.34 & $<0.001$ \\
\hline \multicolumn{5}{|l|}{ Fractions of triglycerides ${ }^{6}(\%)$} \\
\hline Low melting triglycerides & 32.41 & 44.24 & 2.28 & $<0.001$ \\
\hline Middle melting triglycerides & 33.97 & 25.36 & 1.64 & $<0.001$ \\
\hline High melting triglycerides & 33.58 & 30.42 & 0.66 & 0.004 \\
\hline Supercooling $\Delta \mathrm{T}^{7}\left({ }^{\circ} \mathrm{C}\right)$ & 23.13 & 22.34 & 0.42 & 0.380 \\
\hline
\end{tabular}

${ }^{1}$ Applied time-temperature program: holding at $65^{\circ} \mathrm{C}$ for $15 \mathrm{~min}$ to ensure a completely liquid state, cooling at $10^{\circ} \mathrm{C} / \mathrm{min}$ to $-50^{\circ} \mathrm{C}$, holding for $5 \mathrm{~min}$, and then heating at $20^{\circ} \mathrm{C} / \mathrm{min}$ to $65^{\circ} \mathrm{C}$. Values are the mean of $\mathrm{n}=$ 4 determinations.

${ }^{2} \mathrm{CMF}=$ milk fat from cows fed a control diet; $\mathrm{UMF}=$ milk fat from cows fed a diet containing extruded linseed.

${ }^{3}$ Onset of crystallization $=$ temperature at beginning of crystallization.

${ }^{4}$ Offset of melting $=$ temperature at ending of melting.

${ }^{5}$ Offset temperature of high melting triglycerides = melting temperature of anhydrous milk fat.

${ }^{6}$ Low melting triglycerides: fraction melted at temperatures $<10^{\circ} \mathrm{C}$; middle melting triglycerides: fraction melted between 10 and $20^{\circ} \mathrm{C}$; high melting triglycerides: fraction melted $>20^{\circ} \mathrm{C}$.

${ }^{7}$ Supercooling $\Delta \mathrm{T}$ : difference $\left({ }^{\circ} \mathrm{C}\right)$ between the offset temperature of melting of the high melting triglycerides and the onset temperature of crystallization of the first crystallization peak.

$\mathrm{UMF}( \pm 29 \%)$, which may be related to the different amount of HMT in both fats. After an induction period of about 20 min, a second crystallization step occurred, which was similar for both milk fats. During the first crystallization step, HMT were crystallized in the $\alpha$ polymorph for both CMF and UMF (4.11 A; Figure $5 \mathrm{C}, 5 \mathrm{D})$, although for $\mathrm{CMF}$ a higher content of $\alpha$ crystals could be observed. After about $20 \mathrm{~min}$, a second crystallization step could be observed, consisting of a melt-mediated polymorphic transformation of HMT in the $\alpha$ into the $\beta^{\prime}$ polymorph ( 4.25 and $3.85 \AA$ ), which is probably combined with an initial growth of $\beta^{\prime}$ crystals from the melt, consisting of MMT and LMT (Cisneros et al., 2006). At the end of the second crystallization step both the $\alpha$ and $\beta^{\prime}$ polymorphs coexisted.

With isothermal DSC, the onset temperature of crystallization could be quantitatively determined. A lower onset temperature for $\operatorname{UMF}\left(13.9^{\circ} \mathrm{C}\right)$ than for $\mathrm{CMF}$ $\left(15.3^{\circ} \mathrm{C}\right)$ could be observed $(P=0.003)$. This was also confirmed by a shift in the temperature at peak maximum of melting toward lower temperatures for UMF (Table $3 ; P<0.001)$. Finally, the induction time to the second crystallization step was shorter for UMF (13.9 min) compared with CMF (15.3 min; $P=0.091)$.

\section{DISCUSSION}

\section{Influence of Unsaturated Fatty Acids on the SFC Profile}

The differences in fatty acid composition between both milk fats observed in this study are similar to hundreds of studies, published over the last 40 years, on the response of milk fatty acid composition to dietary lipid supplements. Our results confirm the high variability of milk fatty acid composition, with the widest variations being observed in the percentages of medium-chain versus C18 fatty acids, and among the C18 in C18:0, C18:1 cis, and C18:1 trans (Glasser et al., 2008). Because milk fat is composed of $98.3 \%$ triglycerides (Taylor and MacGibbon, 2002), an altered fatty acid profile would also cause a shift in triglyceride composition. In spite of the complexity and stereospecificity of the triglycerides in milk fat, it is expected that a decreased content of SFA and an increased content of MUFA and PUFA for UMF would increase the content of UUU and SUU triglycerides at the expense of the proportion of SSU and SSS compared with CMF (where $\mathbf{S}=$ saturated and $\mathbf{U}=$ unsaturated; Deffense, 1993). Because the greater part of UUU and SUU are liquid at refrigerated 
temperatures, an increased content of unsaturated fatty acids would result in a lower SFC, in particular at these low temperatures.

When cows were fed calcium salts of high oleic sunflower oil, a significantly lower SFC profile was reported by Lin et al. (1996). Chouinard et al. (1998) observed a lower $\mathrm{SFC}$ up to $20^{\circ} \mathrm{C}$ after feeding cows calcium salts of fatty acids from canola oil, soybean oil, and linseed oil, whereas at higher temperatures an SFC similar to that of the control was obtained. They associated the lower SFC at low temperatures with a decrease in the proportion of fatty acids with short and intermediate chain lengths. Couvreur et al. (2006) also observed similar shifts in fatty acid composition when replacing corn silage by fresh grass in the diet; nevertheless, they could not observe large differences in SFC profile. This may be because of the methodology they used, because they used nonisothermal DSC to determine SFC.

\section{Influence of Unsaturated Fatty Acids on Crystallization Behavior of AMF}

In this experiment, a similar degree of supercooling was needed to induce nonisothermal crystallization for both milk fats in spite of the shift in fatty acid composition. It is known that the onset of crystallization is influenced by the degree of supersaturation of a specific triglyceride, which is the ratio of the concentration of a specific triglyceride in the melt initially present to the concentration that is soluble in the melt at a given temperature (Boistelle, 1988). Changing the fatty acid composition of milk fat resulting in a higher content of unsaturated fatty acids would therefore decrease the onset temperature of crystallization, as observed in this experiment. These results are in agreement with the work of Couvreur et al. (2006), who observed a shift in onset temperature of crystallization toward lower temperatures when the proportion of fresh grass in the diet increased.

When investigating isothermal crystallization, a higher content of unsaturated fatty acids resulted in a slower nucleation, a longer induction time to crystallization, and a lower amount of SFC at the end of crystallization, although crystallization occurred according to similar $\alpha-\beta^{\prime}$ polymorphic transitions. In contrast, Singh et al. (2004) observed a shorter induction time, a higher rate constant of crystallization, and a crystallization preferable in the $\beta^{\prime}$ polymorph when cows were fed algae. Although an algae diet also resulted in an enrichment of unsaturated fatty acids, the content of trans-MUFA was particularly increased. These fatty acids showed a higher melting profile, inducing a different crystallization behavior because of the higher degree of supersaturation of the melt compared with cis-MUFA,

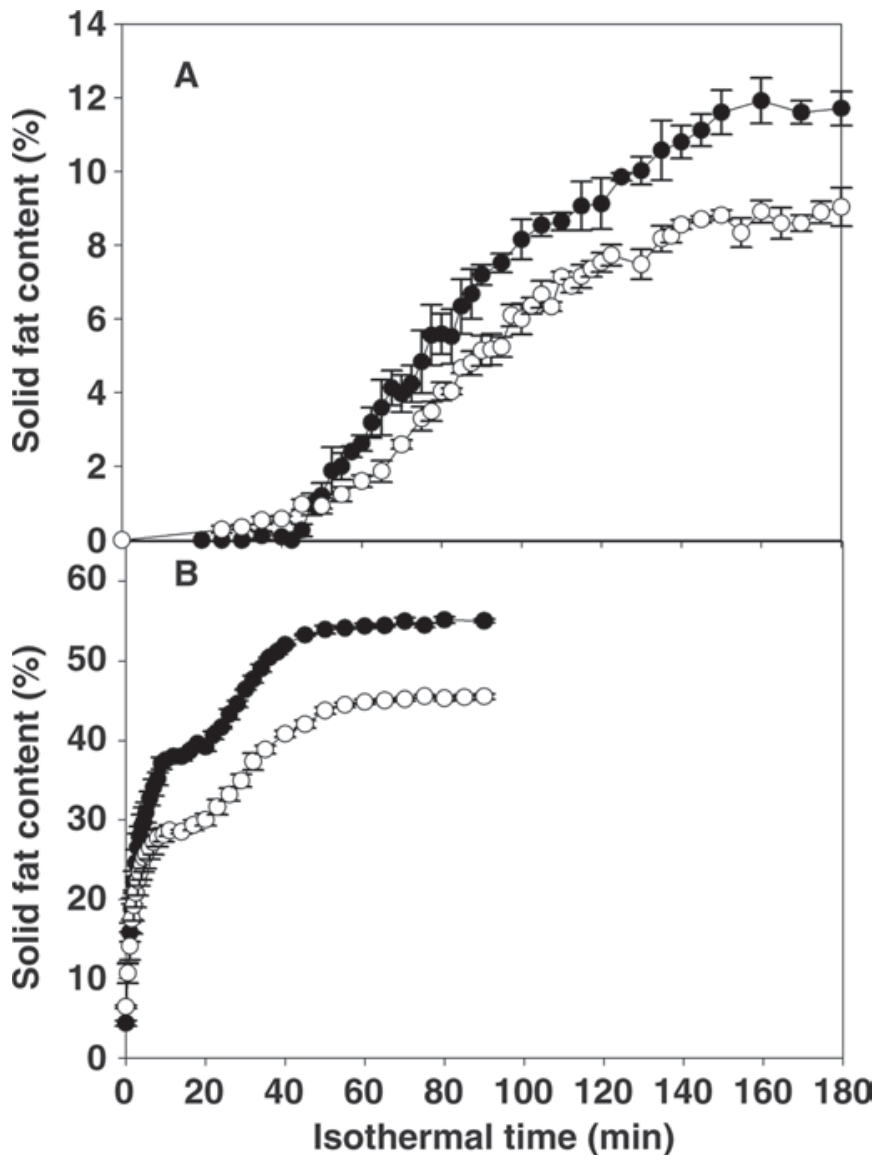

Figure 4. Solid fat content (\%) as a function of time during isothermal crystallization obtained with pulsed nuclear magnetic resonance for milk fat from cows fed a control diet $(\bullet)$ or a diet containing extruded linseed $(O)$, where values are the mean of $n=3$ determinations. A) Supercooling of $14.8^{\circ} \mathrm{C}$; B) supercooling of $31.8^{\circ} \mathrm{C}$.

which were enriched in this study. Shi et al. (2001) also observed a higher crystallization rate for AMF with a higher content of higher melting triglycerides.

\section{Influence of Unsaturated Fatty Acids on Melting Behavior of AMF}

A higher content of unsaturated fatty acids also influenced the melting behavior of AMF. Its melting range was broadened and shifted toward lower temperatures because of the more diverse and more unsaturated triglyceride composition within the crystal lattice. These results were in agreement with the work of Herrera and Hartel (2000), which compared slow and rapid cooling of AMF. In addition, the proportions between the 3 fractions of the melting peak were altered with a strong enrichment of the LMT fraction. These shifts between the different melting fractions are in agreement with Deffense (1993) and Dimick et al. (1996), who postulated that HMT are enriched in SSS and MMT contain 

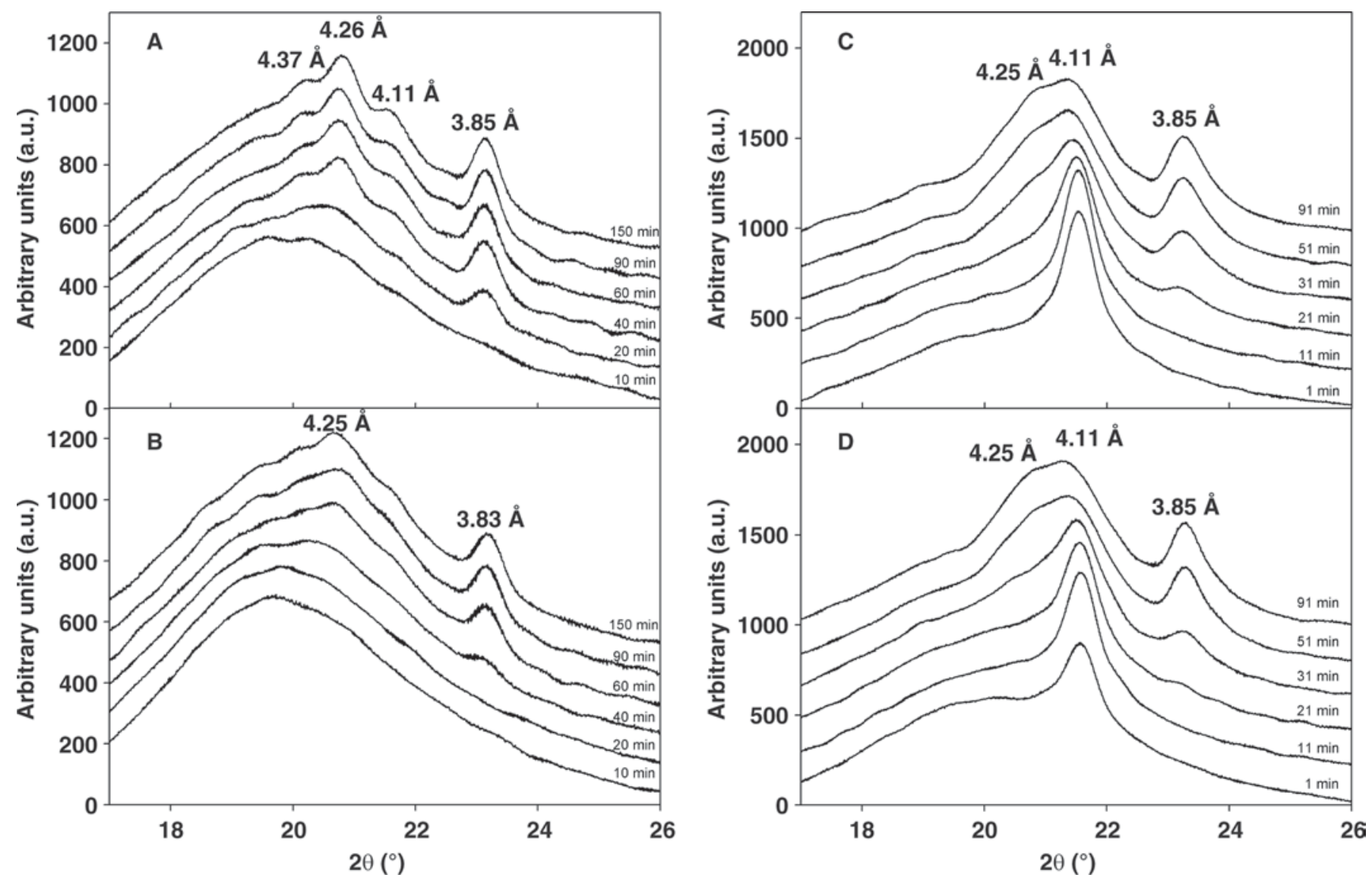

Figure 5. Wide angle x-ray diffraction (WAXD) patterns, in arbitrary units (a.u.), as a function of $2 \theta\left(^{\circ}\right)$. The background has been subtracted, and plots have been offset from their baseline to improve clarity. Corresponding spacing to peak maxima are indicated. A) WAXD patterns for milk fat from cows fed a control diet, isothermally crystallized at $23.7^{\circ} \mathrm{C}$; B) WAXD patterns for milk fat from cows fed a diet containing extruded linseed, isothermally crystallized at $22.0^{\circ} \mathrm{C}$; C) WAXD patterns for milk fat from cows fed a control diet, isothermally crystallized at $6.7^{\circ} \mathrm{C}$; D) WAXD patterns for milk fat from cows fed a diet containing extruded linseed, isothermally crystallized at $5.0^{\circ} \mathrm{C}$.

Table 3. Parameters derived from isothermal crystallization ${ }^{1}$ of anhydrous milk fat obtained with differential scanning calorimetry

\begin{tabular}{|c|c|c|c|c|}
\hline \multirow[b]{2}{*}{ Parameter } & \multicolumn{2}{|c|}{ Milk fat ${ }^{2}$} & \multirow[b]{2}{*}{ SEM } & \multirow[b]{2}{*}{$P$-value } \\
\hline & $\mathrm{CMF}$ & $\mathrm{UMF}$ & & \\
\hline \multicolumn{5}{|l|}{ One-step crystallization } \\
\hline Induction time to crystallization ( $\min$ ) & 26.81 & 35.21 & 2.08 & 0.014 \\
\hline Temperature at peak maximum of melting $\left({ }^{\circ} \mathrm{C}\right)$ & 38.31 & 37.09 & 0.32 & 0.027 \\
\hline Peak width at half height ${ }^{3}\left({ }^{\circ} \mathrm{C} \cdot \mathrm{g} / \mathrm{J}\right)$ & 0.768 & 0.937 & 0.045 & 0.041 \\
\hline \multicolumn{5}{|l|}{ Two-step crystallization } \\
\hline Induction time to second crystallization step (min) & 14.07 & 13.09 & 0.29 & 0.091 \\
\hline Onset of crystallization $\left({ }^{\circ} \mathrm{C}\right)$ & 15.29 & 13.92 & 0.32 & 0.003 \\
\hline Temperature at peak maximum of melting $\left({ }^{\circ} \mathrm{C}\right)$ & 21.73 & 19.09 & 0.59 & $<0.001$ \\
\hline
\end{tabular}

${ }^{1}$ Applied time-temperature program: holding at $65^{\circ} \mathrm{C}$ for $10 \mathrm{~min}$ to ensure a completely liquid state, cooling at $10^{\circ} \mathrm{C} / \mathrm{min}$ to the appropriate crystallization temperature, holding for a given crystallization time to ensure total crystallization, and then heating at $20^{\circ} \mathrm{C} / \mathrm{min}$ to $65^{\circ} \mathrm{C}$. Values are the mean of $\mathrm{n}=3$ determinations.

${ }^{2} \mathrm{CMF}=$ milk fat from cows fed a control diet; $\mathrm{UMF}=$ milk fat from cows fed a diet containing extruded linseed.

${ }^{3}$ Peak width at half height of the melting curve is corrected for the melting enthalpy. 
principally SSU, whereas LMT are mainly composed of SUU and UUU. In addition, the shifted offset temperatures of the melting fractions suggested that the triglyceride composition of each fraction itself was also changed. Couvreur et al. (2006) and Chouinard et al. (1998) observed similar tendencies for shifts between the different melting fractions, because of a decrease in the proportion of fatty acids of short and intermediate chain lengths.

\section{CONCLUSIONS}

In the literature, several studies have demonstrated that the proportion of unsaturated fatty acids may interfere in the production process of dairy products, and the texture of such dairy products may also be changed. However, very little research has been done to reveal the fundamental background of this phenomenon. From this study, it is clear that a higher content of unsaturated fatty acids in AMF resulted in an increased proportion of LMT. These triglycerides lowered the solid fat content profile, particularly at refrigerator temperatures. Furthermore, they induced some changes in the crystallization and melting behavior of milk fat compared with a control AMF, although no fundamental changes in the crystallization mechanism could be revealed. Even though a lower melting point could be observed for milk fat with a higher content of unsaturated fatty acids, a similar degree of supercooling was needed to initiate crystallization, resulting in a shift in onset temperature of crystallization toward lower temperatures. In addition, slower crystallization kinetics were measured, such as a lower nucleation rate and longer induction times, although crystallization occurred in a similar polymorphic crystal lattice. During melting, a shift in offset temperature toward lower temperatures could be observed for the 3 melting fractions of AMF in addition to a higher proportion of low melting triglycerides. In conclusion, we demonstrated in this research that a higher content of unsaturated fatty acids has some effects on the crystallization behavior of milk fat. This knowledge could be used to produce dairy products of similar or superior quality compared with conventional products by intervening in the production process of dairy products.

\section{ACKNOWLEDGMENTS}

This work was funded by a grant of the Flemish Institute for Agricultural and Fisheries Research (ILVO, Melle, Belgium). The authors express their gratitude to B. Norberg (FUNDP, Namur, Belgium) for her kind assistance in the XRD facilities.

\section{REFERENCES}

Ashes, J. R., S. K. Gulati, and T. W. Scott. 1997. Potential to alter the content and composition of milk fat through nutrition. J. Dairy Sci. 80:2204-2212.

Baer, R. J., J. Ryali, D. J. Schingoethe, K. M. Kasperson, D. C. Donovan, A. R. Hippen, and S. T. Franklin. 2001. Composition and properties of milk and butter from cows fed fish oil. J. Dairy Sci. 84:345-353.

Bayourthe, C., F. Enjalbert, and R. Moncoulon. 2000. Effects of different forms of canola oil fatty acids plus canola meal on milk composition and physical properties of butter. J. Dairy Sci. 83:690-696.

Bobe, G., E. G. Hammond, A. E. Freeman, G. L. Lindberg, and D. C. Beitz. 2003. Texture of butter from cows with different milk fatty acid compositions. J. Dairy Sci. 86:3122-3127.

Boistelle, R. 1988. Fundamentals of nucleation and crystal growth. Pages 189-276 in Crystallization and Polymorphism of Fats and Fatty Acids. N. Garti and K. Sato, ed. Marcel Dekker Inc., New York, NY.

Chen, S., G. Bobe, S. Zimmerman, E. G. Hammond, C. M. Luhman, T. D. Boylston, A. E. Freeman, and D. C. Beitz. 2004. Physical and sensory properties of dairy products from cows with various milk fatty acid compositions. J. Agric. Food Chem. 52:3422-3428.

Chouinard, P. Y., V. Girard, and G. J. Brisson. 1998. Fatty acid profile and physical properties of milk fat from cows fed calcium salts of fatty acids with varying unsaturation. J. Dairy Sci. 81:471-481.

Cisneros, A., G. Mazzanti, R. Campos, and A. G. Marangoni. 2006. Polymorphic transformation in mixtures of high- and low-melting fractions of milk fat. J. Agric. Food Chem. 54:6030-6033.

Couvreur, S., C. Hurtaud, C. Lopez, L. Delaby, and J. L. Peyraud. 2006. The linear relationship between the proportion of fresh grass in the cow diet, milk fatty acid composition, and butter properties. J. Dairy Sci. 89:1956-1969.

Deffense, E. 1993. Milk fat fractionation today: A review. J. Am. Oil Chem. Soc. 70:1193-1201.

Dewhurst, R. J., N. D. Scollan, M. R. F. Lee, H. J. Ougham, and M. O. Humphreys. 2003. Forage breeding and management to increase the beneficial fatty acid content of ruminant products. Proc. Nutr. Soc. $62: 329-336$

Dewhurst, R. J., K. J. Shingfield, M. R. F. Lee, and N. D. Scollan. 2006. Increasing the concentrations of beneficial polyunsaturated fatty acids in milk produced by dairy cows in high-forage systems. Anim. Feed Sci. Technol. 131:168-206.

Dimick, P. S., S. Yella Reddy, and G. R. Ziegler. 1996. Chemical and thermal characteristics of milk-fat fractions isolated by a melt crystallization. J. Am. Oil Chem. Soc. 73:1647-1652.

Driessen, F. M., A. Jellema, F. J. P. Van Luin, J. Stadhouders, and G. J. M. Wolbers. 1977. The estimation of the fat acidity in raw milk. An adaptation of the BDI method, suitable for routine assay. Neth. Milk Dairy J. 31:40-55.

Givens, D. I., and K. J. Shingfield. 2003. Improving the nutritional quality of milk. Pages 515-531 in Dairy Processing, Improving Quality. G. Smit, ed. Woodhead Publishing Ltd., Cambridge, UK.

Glasser, F., A. Ferlay, and Y. Chilliard. 2008. Oilseed lipid supplements and fatty acid composition of cow milk: A meta-analysis. J. Dairy Sci. 91:4687-4703.

Gonzalez, S., S. E. Duncan, S. F. O'Keefe, S. S. Sumner, and J. H. Herbein. 2003. Oxidation and textural characteristics of butter and ice cream with modified fatty acid profiles. J. Dairy Sci. 86:70-77.

Herrera, M. L., and R. W. Hartel. 2000. Effect of processing conditions on crystallization kinetics of a milk fat model system. J. Am. Oil Chem. Soc. 77:1177-1187.

Jones, E. L., K. J. Shingfield, C. Kohen, A. K. Jones, B. Lupoli, A. S. Grandison, D. E. Beever, C. M. Williams, P. C. Calder, and P. Yaqoob. 2005. Chemical, physical, and sensory properties of dairy products enriched with conjugated linoleic acid. J. Dairy Sci. 88:2923-2937. 
Kaylegian, K. E., R. W. Hartel, and R. C. Lindsay. 1993. Applications of modified milk fat in food products. J. Dairy Sci. 76:17821796.

Kaylegian, K. E., and R. C. Lindsay. 1995. Handbook of Milk Fat Fractionation Technology and Applications. AOCS Press, Champaign, IL.

Lin, M. P., C. A. Sims, C. R. Staples, and S. F. O'Keefe. 1996. Flavor quality and texture of modified fatty acid high monoene, low saturate butter. Food Res. Int. 29:367-371.

Lock, A. L., and D. E. Bauman. 2004. Modifying milk fat composition of dairy cows to enhance fatty acids beneficial to human health. Lipids 39:1197-1206.

Lopez, C., P. Lesieur, C. Bourgaux, and M. Ollivon. 2005. Thermal and structural behavior of anhydrous milk fat. 3. Influence of cooling rate. J. Dairy Sci. 88:511-526.

Noakes, M., P. J. Nestel, and P. M. Clifton. 1996. Modifying the fatty acid profile of dairy products through feedlot technology lowers plasma cholesterol of humans consuming the products. Am. J. Clin. Nutr. 63:42-46.

Poppitt, S. D., G. F. Keogh, T. B. Mulvey, B. H. McArdle, A. K. H. MacGibbon, and G. J. S. Cooper. 2002. Lipid-lowering effects of a modified butter-fat: A controlled intervention trial in healthy men. Eur. J. Clin. Nutr. 56:64-71.

Seidel, C., T. Deufel, and G. Jahreis. 2005. Effects of fat-modified dairy products on blood lipids in humans in comparison with other fats. Ann. Nutr. Metab. 49:42-48.
Shi, Y., C. M. Smith, and R. W. Hartel. 2001. Compositional effects on milk fat crystallization. J. Dairy Sci. 84:2392-2401.

Singh, A. P., C. A. Avramis, J. K. Kramer, and A. G. Marangoni. 2004. Algal meal supplementation of the cows' diet alters the physical properties of milk fat. J. Dairy Res. 71:66-73.

Smet, K., J. De Block, S. De Campeneere, D. De Brabander, L. Herman, K. Raes, K. Dewettinck, and K. Coudijzer. 2009. Oxidative stability of UHT milk as influenced by fatty acid composition and packaging. Int. Dairy J. 19:372-379.

Smet, K., K. Raes, J. De Block, L. Herman, K. Dewettinck, and K. Coudijzer. 2008. A change in antioxidative capacity as a measure of onset to oxidation in pasteurized milk. Int. Dairy J. 18:520-530.

Taylor, M. W., and A. K. H. MacGibbon. 2002. Lipids. Pages 15441626 in Encyclopedia of Dairy Sciences. H. Roginski, J. W. Fuquay, and A. F. Fox, ed. Academic Press, London, UK.

ten Grotenhuis, E., G. A. van Aken, K. F. van Malssen, and H. Schenk. 1999. Polymorphism of milk fat studied by differential scanning calorimetry and real-time X-ray powder diffraction. J. Am. Oil Chem. Soc. 76:1031-1039.

Tholstrup, T., B. Sandstrom, J. E. Hermansen, and G. Holmer. 1998 Effect of modified dairy fat on postprandial and fasting plasma lipids and lipoproteins in healthy young men. Lipids 33:11-21.

Timms, R. E. 1980. The phase behaviour and polymorphism of milk fat, milk fat fractions and fully hardened milk fat. Aust. J. Dairy Technol. 35:47-53. 